\title{
THE APPLICATION OF OPTOELECTRONIC SET FOR MEASURING RELATIVE MOVEMENTS OF ROCK BLOCKS
}

\author{
Kazimierz ĆMIELEWSKI, Piotr GOLUCH, \\ Janusz KUCHMISTER and Izabela WILCZYŃSKA
}

Institute of Geodesy and Geoinformatics, Wroclaw University of Environmental and Life Sciences, Grunwaldzka 53, 50-357 Wroclaw, Poland

*Corresponding author's e-mail: kazimierz.cmielewski@up.wroc.pl

\begin{tabular}{l} 
ARTICLE INFO \\
\hline Article history: \\
Received 1 December 2014 \\
Accepted 9 February 2015 \\
Available online 2 March 2015 \\
\hline
\end{tabular}

Keywords:

Rock mass deformation measurements Close-range mono-photogrammetry Optoelectronic technique

\begin{abstract}
The article presents a new method for measuring relative displacements of rock blocks using the optoelectronic technique. Due to the fact that very precise optoelectronic devices are available on the market, it is possible to design various sets of measuring instruments. The proposed measuring kit consists of a set of lasers arranged in configurations identified by the project and $\mathrm{CCD} / \mathrm{CMOS}$ camera, which is a measuring receiver.

The measuring set designed and developed by the authors of the paper can be successfully used to monitor the relative displacements at short distances e.g. of rock blocks and monadnocks, in the cave corridors, in adits and water dam galleries. This method is based on angular intersection accomplished with laser beams, which are recorded by the CCD/CMOS camera. The tests were performed in 3 cycles for the following distances between the transmitter and the receiver: $38.5 \mathrm{~cm}, 78.0 \mathrm{~cm}$ and $153 \mathrm{~cm}$. The obtained results of the measurements were subjected to statistical analysis based on the test: Student's t and F Fisher-Snedecor. Initial research and experimental works with a prototypical measuring set carried out by the authors in the laboratory enabled to determine the simulated displacements with the measurement accuracy better than $\pm 0.06 \mathrm{~mm}$ (about 1 pixel).
\end{abstract}

\section{INTRODUCTION}

Natural processes that occur on natural objects cause cracking and displacement of the rock blocks, and on technical objects (e.g. dams, weirs) displacements and deformations in their structure. These processes pose danger to humans and environment and cause catastrophes and breakdowns of technical objects. Thus, it is necessary to use control and surveying devices to monitor places where the above-mentioned phenomena may occur.

Geodetic measurements performed on inanimate and engineering objects feature various accuracies. Due to the type and the accuracy of measurements, the following 3 measuring segments may be specified (Cacoń, 2001):

- $\quad$ segment I - GPS satellite observations and precise levelling (where the accuracy of displacement measurements averages $\pm 0.5 \div 10 \mathrm{~mm}$ ),

- $\quad$ segment II - observations as above enriched with total stations (accuracy of displacement measurements is: $\pm 0.5 \div 2 \mathrm{~mm}$ ),

- $\quad$ segment III - relative measurements (accuracy of displacement measurements is: $\pm 0.01 \div 0.1 \mathrm{~mm}$ ).

This paper presents the method of measuring relative displacements of rock blocks based on traces of laser dots registered on the recorder screen.

Geometric analyses of the test object behaviour can be used to specify:
- object displacements,

- object deformations,

- displacements of the object bed rock.

A displacement means the repositioning of the object points without altering the shape of the object (the mutual distance of the test point)-in the geometric interpretation it consists of translations and rotations. The deformation is the change of the position of object points resulting from the changes in the shape of the object - in geometric interpretation it means: change of scale, torsion, buckling and deflection.

The displacement vector is the vector connecting the position of a point at the initial moment with this point location at the final moment, while the point position change is considered within a specified interval of time and in the adopted reference system.

Nowadays, on important objects the indications of measuring devices are continuously being monitored. To investigate the relative movements of the object (in particular changes in the distance between points, changes in the altitude of points, or plumb line variations) specialist instruments are used which enable to measure with the accuracy of a few hundredths of a millimetre (Kavvadas, 2003; Mora, 1998; Pelzer, 1988). Control and survey instruments used in measuring displacements include:

- $\quad$ strain gauges and dial indicators (mechanical and electronic), 


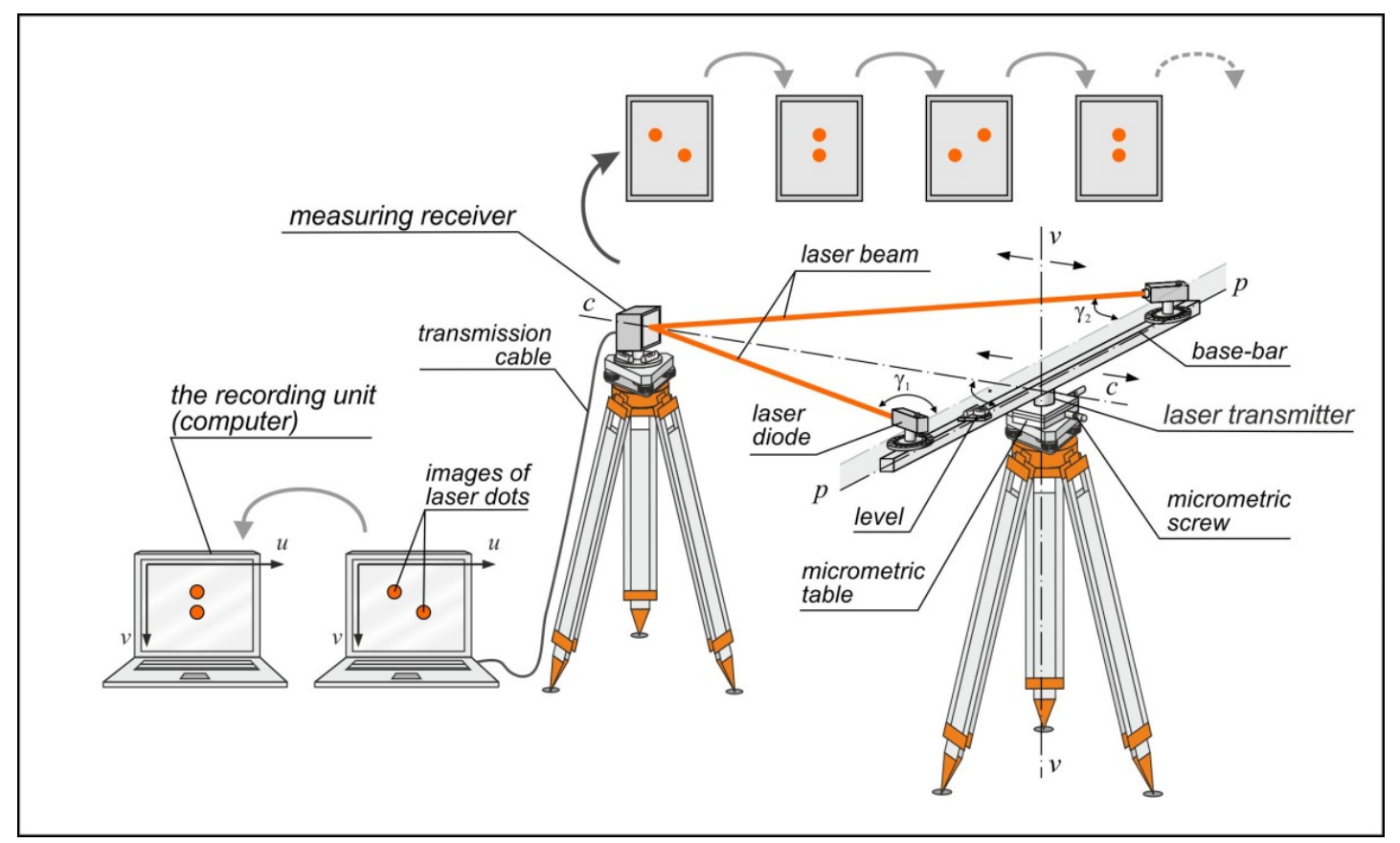

Fig. 1 The gist of the displacement measurement using a single measurement module and sample views of registered images of laser dots.

where: $p$ - $p$-longitudinal axis of the base-bar, $c$-c-travel axis of the longitudinal transmitter, $v$-v-vertical axis of the transmitter, $\gamma_{1}$ and $\gamma_{2}$-angles between the laser beams and the $p$ - $p$ longitudinal axis of the base-bar.

- dilatometers and gap gauges,

- tiltmeters and inclinometers,

- optical plummets and plumb bobs,

- pendulums.

Natural processes which occur on natural objects cause cracking and displacement of the rock blocks. These processes pose danger to humans and environment and cause catastrophes.

Thus, it is necessary to use the control and surveying devices to monitor the places where the above-mentioned phenomena may occur (Hanzl, 2011). In this article the authors presented the measuring set for monitoring these phenomena. It is a prototype Laser Measuring $\underline{\text { Set }}$ (LMS) designed and developed by the authors of this paper. The measuring set can be used to monitor the relative displacements at short distances e.g. of rock blocks and monadnocks, in the cave corridors, in adits and water dam galleries.

\section{DESIGN OF THE LASER MEASURING SET (LMS)}

The presented method of measurement relies on the angular intersection made (Mora, 1998; Schofield and Breach, 2007) from a permanent base with the use of laser beams (Fig. 1). Images of laser dots are recorded by the measuring receiver equipped with the $\mathrm{CCD} / \mathrm{CMOS}$ camera. Figure 1 shows the gist of the displacement measurement using a single measurement module (two laser transmitters). This figure also shows examples of registered images of laser dots, when the micrometric screw moves the laser transmitters along the $c-c$ axis.

The LMS developed by the authors of this paper may appear in different configurations (Fig. 2), depending on the number and distribution of the laser transmitters (measuring points).

Measuring module with two laser diodes (Fig. 2A) located on one of the base-bar (single measurement module) enables to determine distance changes between rock blocks in the horizontal direction.

The principle of measuring the distance relative changes using the two-point measuring module is presented in Figure 2B. When rock blocks change their mutual position in the horizontal plane, the location of laser dots varies on the screen of the measuring receiver. By identifying energy centres of individual images of laser dots it was possible to establish the initial distance $D_{o}$ and the current distance $D_{i}$ between rock blocks (Fig. 2B). Such observations can be used to determine the change in distance between rock blocks in every observation cycle.

In order to determine the relative displacements of rock blocks in the space, multi-point measuring module, in which the laser transmitters are arranged on a set plane, needs to be used. Figures $2 \mathrm{C}$ and $2 \mathrm{D}$ depict two options of the multi-point measuring modules. These are sample configurations of sets comprising of five and nine laser diodes respectively and images of laser dot traces recorded by the $\mathrm{CCD} / \mathrm{CMOS}$ camera of the measuring receiver. 


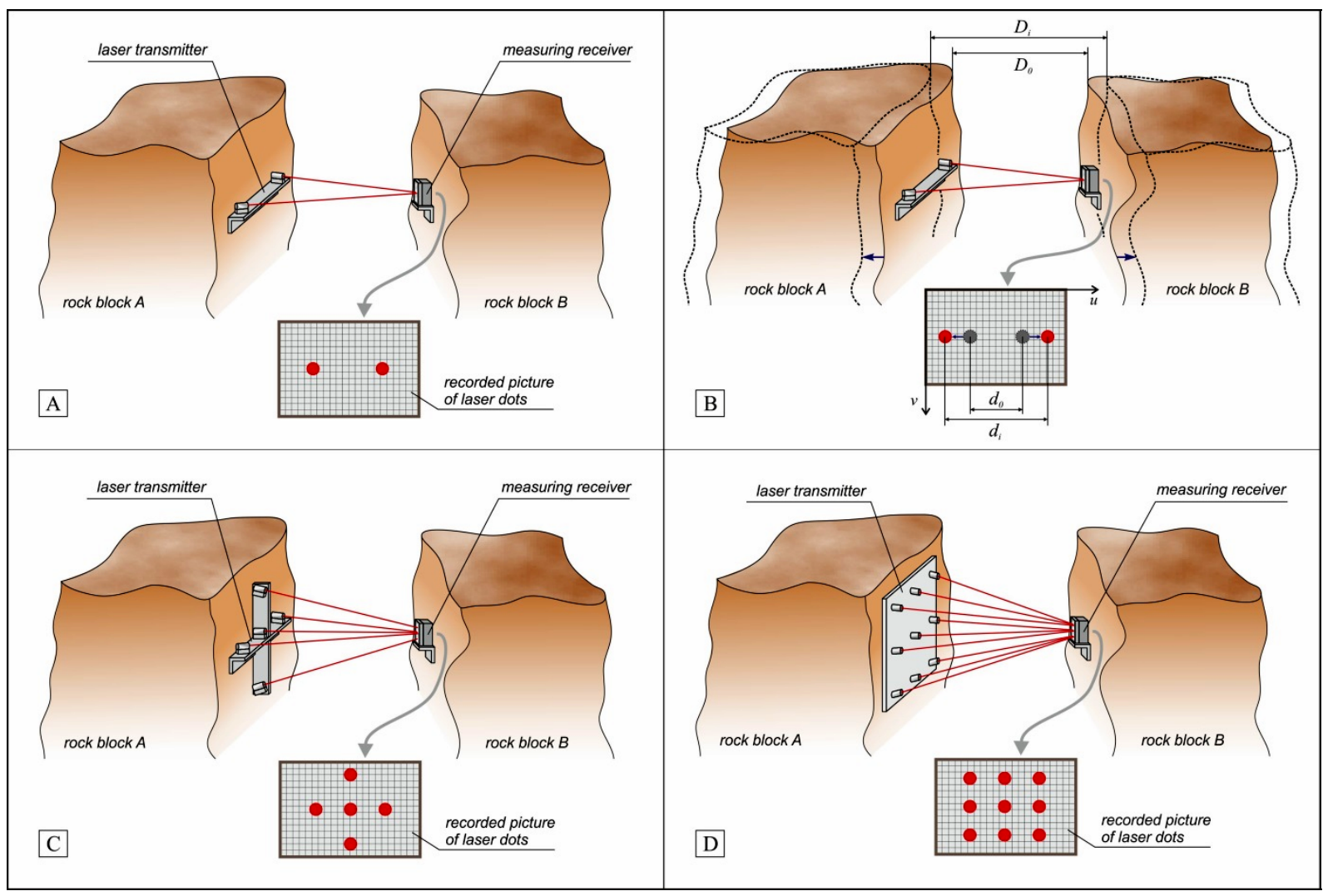

Fig. 2 Sample configurations of the laser measuring sets:

A. two-point (single) measurement module;

B. the principle of relative distance changes measurement with a single measurement module;

C. multi-point measuring module - option I;

D. multi-point measuring module - option II;

where: $u, v$-image local coordinate system, $d_{0}$-the initial distance between the traces of laser dots on a registered image, $d_{i}$-current distance between the traces of laser dots on a registered image, $D_{0}$-initial distance between monitored rock blocks A and $\mathrm{B}, D_{i}$-current distance between the monitored rock blocks A and B.

\section{RESEARCH AND EXPERIMENTAL WORKS}

Experimental works were carried out in order to verify the correctness of the geometric parameters of the prototypical measuring set and to determine its accuracy parameters: repeatability of measurement results and sensitivity at different distances between the transmitter and the receiver. The aim of the research works was also to develop a calibration method for the measuring system based on observations made following the set criteria.

Figure 3 presents the deployment of measuring equipment during the laboratory research and experimental works.

The tribrach equipped with a micrometric table which moves in the horizontal plane along the $\mathrm{x}$ and $\mathrm{y}$ axis within $25 \mathrm{~mm}$ (with accuracy $\pm 0.01 \mathrm{~mm}$ ) is set on the observation pole. A horizontal base-bar (single measurement module) with two laser transmitters (laser diodes) located in the distance $B=750 \mathrm{~mm} \mathrm{(} B$ base length) is attached to the micrometric table. The diodes are placed under a fixed (constant) angle to the surface of the measuring receiver screen (camera with 640x480 resolution CMOS sensor - Video Resolution 300 Kpix). Measuring receiver is set on the tribrach attached to the head of the engineering surveying tripod.
During the test works which depend on using the micrometric screw to move the measuring module at set values in the direction to or from the measuring receiver (along the receiver $c-c$ axis - Fig. 1), the images of laser dots were registered on the receiver screen. The images of laser dots registered by the camera were then transmitted to the computer.

For each position of the measuring module set with the micrometric screw, 48 images of the screen with laser dots were registered. Figure 4 shows the samples of registered photos of receiver's screen with laser dots image.

Images were recorded as 10 -second videos (5 frames per second). This allowed for greater accuracy of the identification of the laser dot energy centre than in case of registering a single image. This enabled to minimise the influence of environmental, thermal and acoustic conditions on the identification of the laser dot energy centre. In order to identify energy centres of individual laser dots (Cyganek and Siebert, 2009; Pears et al., 2012) a modified version of the original program (Gołuch et al., 2012) was used.

The measuring module was moved $n=61$ times by $0.50 \mathrm{~mm}$ or $1.00 \mathrm{~mm}$ towards the measuring receiver and back (within $\pm 5 \mathrm{~mm}$ ). The observation results are gathered in the survey documentation. 


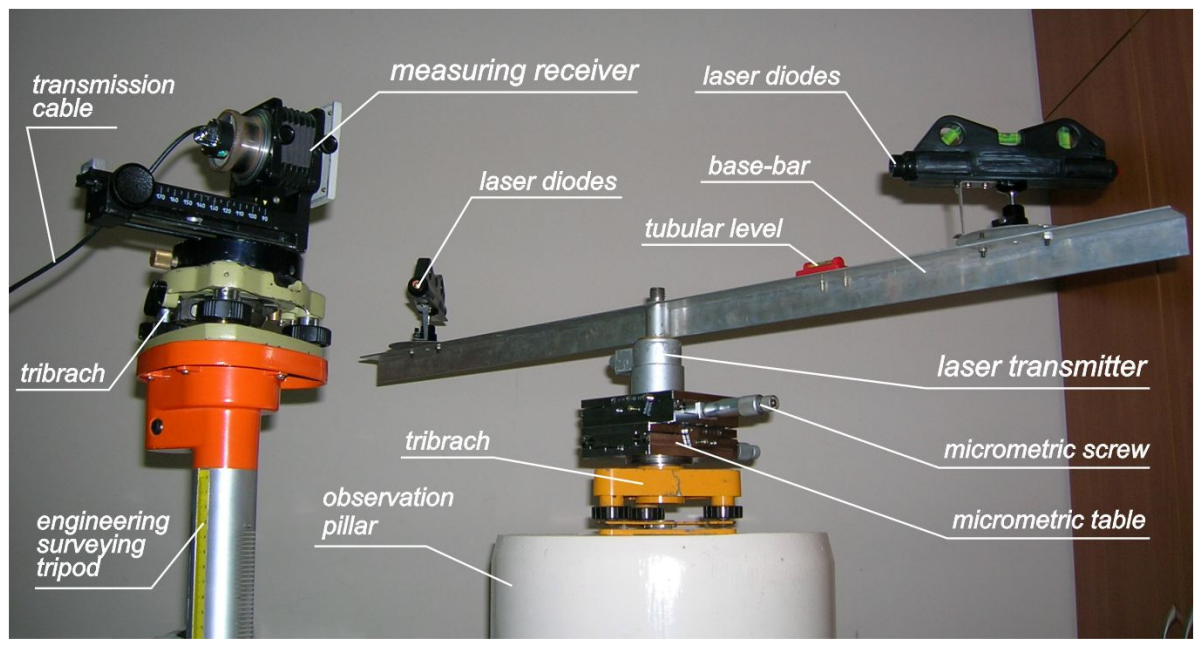

Fig. 3 The location of the measuring equipment during the test works.
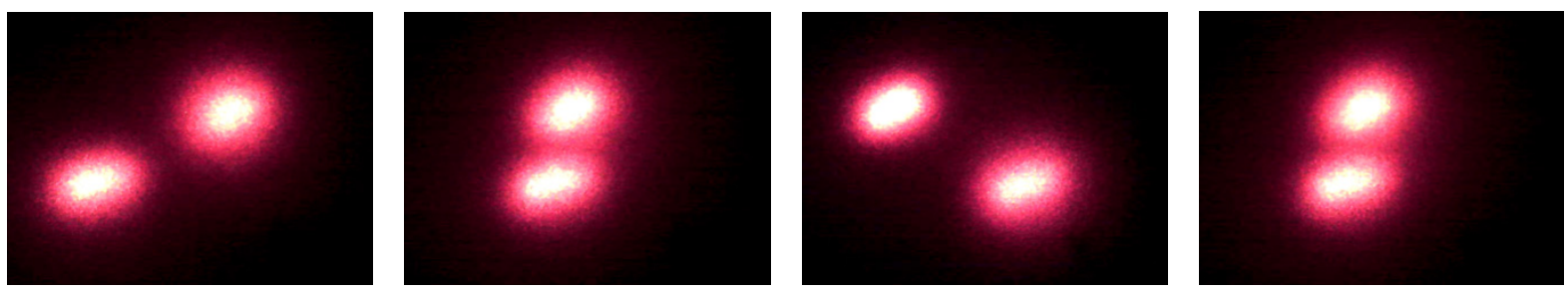

Fig. 4 The samples of registered images of the screen with laser dots.

The tests were performed in 3 cycles for the following distances $D_{i}$ between the transmitter and the receiver:

- $\quad 38.5 \mathrm{~cm}$ - this is half of the base length (base ratio $B / D \cong 2: 1)$

- $78.0 \mathrm{~cm}$ - this is the approximate length of the base $(B / D \cong 1: 1)$,

- $\quad 153 \mathrm{~cm}$ - this is approximately twice the length of the base $(B / D \cong 1: 2)$.

Additional observations in each of the measuring position enable to determine averaged values and the following types of errors:

- the average error of the single measurement;

- the weighted average error,

which characterize the repeatability of the measurement results. In addition, on the basis of extra observations, and for different distances between the transmitter and the receiver, sensitivity of the device was determined.

Table 1 shows the results obtained for the first measuring cycle (the length of the base is $38.5 \mathrm{~cm}$ ) for three sample settings of the measuring module. Full cycle covered 34 measuring positions, and in each position from 2 to 9 settings of the measuring transmitter were recorded (95 measurements in total). For each setting of the measuring transmitter 48 images were recorded. On the basis of the measurement results, the accuracy of the measurements for each setting of the measuring module was determined as the weighted average error.
Weights in the calculation of the weighted average comprised the inverses of the laser spot position errors. This accuracy is at the level of $0.2-0.3$ pixel (these are sub-pixel values).

Figure 5 shows the relationship between the location of the laser dot traces (left and right) and the movement of the measuring transmitter in the direction from/to a measuring receiver (along the $c-c$ axis of the transmitter-Fig. 1) arranged by the movements of the micrometric screw.

The graphs are not linear and they have different inclination angles with respect to the horizontal axis of the chart because errors of the camera lens distortions occur, the base-bar ( $p-p$ axis of the transmitter) is not parallel to the measuring receiver screen and angles $\gamma_{1}$ and $\gamma_{2}$ of the laser transmitter differ (Fig. 1). These mistakes and unfulfilled geometric conditions of the measuring set are eliminated through the correct calibration of the device.

Calibration of the measuring set consisted in eliminating of impact of the camera's optical distortion errors (correction of the measurement results) (Brown, 1971; Gruen and Huang, 2001) and designating parameters of two ninth degree polynomials (Formula 1). The measurement results which described location of each dot after appropriate setting of the transmitter were approximated.

$$
\hat{\boldsymbol{Y}}_{\boldsymbol{i}}=\boldsymbol{a}_{1} \boldsymbol{X}_{\boldsymbol{i}}+\boldsymbol{a}_{2} \boldsymbol{X}_{i}^{2}+\cdots+\boldsymbol{a}_{\boldsymbol{k}} \boldsymbol{X}_{i}^{\boldsymbol{k}}+\boldsymbol{b}
$$

For the both approximating functions that were determined, we conducted statistical analyses of 
Table 1 Evaluation of the repeatability of measurements using a prototype LMS for the three set sample settings of the measuring module.

\begin{tabular}{|c|c|c|c|c|c|c|c|c|c|}
\hline \multirow{4}{*}{$\begin{array}{l}\text { The value of the } \\
\text { travel of the } \\
\text { measuring module } \\
\text { set with the } \\
\text { micrometric screw } \\
\text { along the } c-c \text { axis } \\
\text { of the transmitter } \\
\text { [mm] }\end{array}$} & \multirow{3}{*}{$\begin{array}{c}\begin{array}{c}\text { The number } \\
\text { of registered } \\
\text { images }\end{array} \\
n\end{array}$} & \multicolumn{8}{|c|}{ The designated location of the laser dot and its position error } \\
\hline & & \multicolumn{4}{|c|}{ Upper (left) laser dot } & \multicolumn{4}{|c|}{ Bottom (right) laser dot } \\
\hline & & $x$ & & $m_{x}$ & & $x$ & $y$ & $\boldsymbol{m}_{x}$ & $\boldsymbol{m}_{y}$ \\
\hline & [pc] & [pix] & [pix] & [pix] & [pix] & [pix] & [pix] & [pix] & [pix] \\
\hline \multirow{4}{*}{5.0} & 48 & 418.32 & 178.12 & 0.54 & 0.60 & 126.94 & 298.86 & 0.54 & 0.26 \\
\hline & 48 & 418.32 & 178.27 & 0.71 & 0.51 & 126.25 & 298.99 & 1.18 & 0.72 \\
\hline & 48 & 418.74 & 177.98 & 1.03 & 0.32 & 124.92 & 299.02 & 0.80 & 0.32 \\
\hline & 48 & 417.58 & 178.09 & 0.45 & 0.33 & 125.04 & 299.09 & 0.84 & 0.44 \\
\hline \multicolumn{2}{|c|}{ the weighted average and its error } & 418.13 & 178.10 & 0.24 & 0.06 & 125.90 & 298.97 & 0.52 & 0.05 \\
\hline \multirow{4}{*}{6.0} & 48 & 391.50 & 175.64 & 0.39 & 0.40 & 150.25 & 300.33 & 0.92 & 0.68 \\
\hline & 48 & 391.32 & 175.23 & 0.65 & 0.33 & 150.22 & 300.47 & 0.77 & 0.34 \\
\hline & 48 & 392.04 & 175.87 & 0.49 & 0.67 & 149.39 & 299.86 & 1.05 & 0.42 \\
\hline & 48 & 391.73 & 175.92 & 0.94 & 0.47 & 149.33 & 300.25 & 0.81 & 0.51 \\
\hline \multicolumn{2}{|c|}{ the weighted average and its error } & 391.65 & 175.61 & 0.16 & 0.17 & 149.81 & 300.23 & 0.25 & $\mathbf{0 . 1 4}$ \\
\hline \multirow{4}{*}{7.0} & 48 & 367.70 & 172.65 & 0.66 & 0.56 & 175.26 & 301.61 & 1.00 & 0.53 \\
\hline & 48 & 368.10 & 172.47 & 0.92 & 0.51 & 176.00 & 301.64 & 0.81 & 0.49 \\
\hline & 48 & 368.19 & 171.87 & 0.79 & 0.64 & 175.33 & 301.21 & 0.64 & 0.64 \\
\hline & 48 & 368.38 & 173.20 & 0.51 & 0.52 & 175.39 & 301.47 & 0.62 & 0.52 \\
\hline \multicolumn{2}{|c|}{ the weighted average and its error } & 368.11 & 172.58 & 0.15 & 0.27 & 175.49 & 301.46 & 0.16 & 0.11 \\
\hline
\end{tabular}

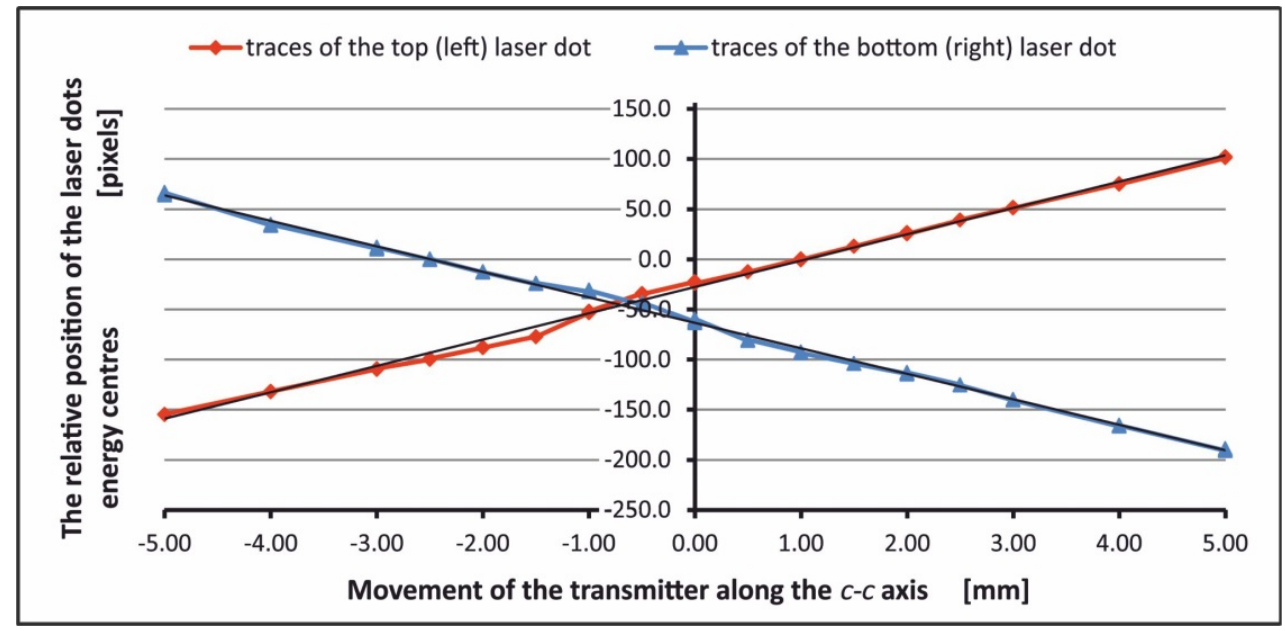

Fig. 5 Repositioning of the energy centres of the registered laser dots in the function of the distance change between the transmitter and the receiver.

function coefficients, i.e. the relevance verification of approximating functions coefficients (Freedman, 2005; Höpcke, 1980). This analysis was carried out on the basis of the tests: $t$-Student's (in order to detect negligible coefficients of the approximating function Formulas 2 and 3) and F Fisher-Snedecor's (to examine the relevance of polynomial regression and to find answers to the question whether the results obtained for high $R^{2}$ values were accidental) Formulas 4 and 5.

$$
\boldsymbol{t}_{\text {emp }_{j}}=\frac{\boldsymbol{a}_{j}}{\boldsymbol{s}_{\boldsymbol{a}_{j}}}
$$




$$
\begin{aligned}
& \left.\left|\boldsymbol{t}_{\text {emp }_{j}}\right|\right\rangle \boldsymbol{t}_{\alpha, \text { df }} \boldsymbol{d f S E}_{\text {SE }} \\
& F_{d f_{S S R}, d f_{S S E}}=\frac{M S R}{M S E}=\frac{\frac{S S Y-S S E}{k}}{\frac{S S Y}{n-k-1}}=\frac{\frac{R^{2}}{k}}{\frac{1-R^{2}}{n-k-1}} \\
& \boldsymbol{R}^{2}=\frac{\boldsymbol{S S R}}{\boldsymbol{S S Y}}=\frac{\sum_{i=1}^{n}\left(\hat{\boldsymbol{Y}}_{i}-\overline{\boldsymbol{Y}}\right)^{2}}{\sum_{i=1}^{n}\left(\boldsymbol{Y}_{i}-\overline{\boldsymbol{Y}}\right)^{2}}=\frac{\boldsymbol{S S Y}-\boldsymbol{S S E}}{\boldsymbol{S S Y}}= \\
& =\frac{\sum_{i=1}^{n}\left(\boldsymbol{Y}_{\boldsymbol{i}}-\overline{\boldsymbol{Y}}\right)^{2}-\sum_{i=1}^{n}\left(\boldsymbol{Y}_{\boldsymbol{i}}-\hat{\boldsymbol{Y}}\right)^{2}}{\sum_{i=1}^{n}\left(\boldsymbol{Y}_{\boldsymbol{i}}-\overline{\boldsymbol{Y}}\right)^{2}}
\end{aligned}
$$

The following notation is used in this work:

$$
\begin{aligned}
& \hat{\boldsymbol{Y}} \quad-\text { dependent variable predicted by } \\
& \text { the regression model }
\end{aligned}
$$

$\boldsymbol{a}_{\boldsymbol{j}}(\boldsymbol{j}=1,2, \ldots \boldsymbol{k})-\mathrm{j}^{\text {th }}$ coefficient corresponding to $\boldsymbol{X}_{\boldsymbol{i}}^{\boldsymbol{j}}$ $\boldsymbol{s}_{a j}(\boldsymbol{j}=1,2, \ldots \boldsymbol{k})-\mathrm{j}^{\text {th }}$ standard error for that coefficient

$b$

$s_{b}$

$k$

\section{$a_{j}$}

- intercept (or constant)

- standard error of the constant $b$

- number of polynomial degree, number of coefficients, number of parameters excluding constant

$$
\boldsymbol{p}=\boldsymbol{k}+1 \quad \text { - total number of parameters }
$$$$
\text { including intercept (constant) }
$$

$$
\overline{\boldsymbol{Y}}=\frac{\sum_{i=1}^{n} \boldsymbol{Y}_{i}}{\boldsymbol{n}} \quad-\text { mean of } Y
$$

$M S R=\frac{S S R}{d f_{S S R}} \quad-$ regression mean square

$\boldsymbol{M S E}=\frac{\boldsymbol{S S E}}{d f_{S S E}} \quad-$ error mean square

$\boldsymbol{S S R}=\sum_{i=1}^{n}\left(\hat{\boldsymbol{Y}}_{i}-\overline{\boldsymbol{Y}}\right)^{2}-$ regression sum of squares

$\boldsymbol{S S E}=\sum_{i=1}^{n}\left(\boldsymbol{Y}_{\boldsymbol{i}}-\hat{\boldsymbol{Y}}_{\boldsymbol{i}}\right)^{2}-$ sum of squares of error (residuals)

$\boldsymbol{S S Y}=\boldsymbol{S S R}+\boldsymbol{S S E}=\sum_{i=1}^{n}\left(\boldsymbol{Y}_{i}-\overline{\boldsymbol{Y}}\right)^{2}-$ total sum of squares

$\boldsymbol{d} \boldsymbol{f}_{S S E}=\boldsymbol{n}-\boldsymbol{k}-1 \quad-$ degrees of freedom for errors

$d f_{S S R}=\boldsymbol{k} \quad-$ degrees of freedom for regression

$\boldsymbol{d} \boldsymbol{f}_{S S Y}=\boldsymbol{d} f_{S S R}+\boldsymbol{d} f_{S S E}=n-1-$ total degrees of freedom
Tables 2 and 3 summarize the results of calculations and statistical analyses. The verification procedures were performed for the statistical significance level $\alpha=0.05$. At the beginning of statistical analyses the critical value of the test $t_{\alpha, v 2}$ were determined for observations that characterize the position of both laser dots (for the left dot $t_{0.05,49}=$ 2.010 and for the right dot $\left.t_{0.05,48}=2.011\right)$. By comparing these values with calculated $t$ - statistics of all polynomial parameters (coefficient value and constant value was divided by its standard error Formulas 2 and 3) we found regression importance of obtained coefficient of the approximating function.

Secondly, on the basis of observations the values of $F$-statistics (for traces of the left $\operatorname{dot} F_{L}=22357.0$ and the right $\operatorname{dot} F_{R}=27872.9$ ) were determined. They were then compared with the critical value $F_{\alpha, v 1, v 2}$ of the F-Snedecor's distribution (for the left $\operatorname{dot} F_{0.05,11,49}=1.99$ and the right $\operatorname{dot} F_{0.05,12,48}=1.96$ ). On this basis we concluded that the approximating polynomial has all coefficients correctly selected. This fact also confirms the respective coefficients of determination: $R_{L}^{2}=0.99980$ and $R_{R}^{2}=0.99986$.

Figure 6 shows the results of the calibration of the measuring set. The thirteenth degree polynomials were adjusted to the distribution of survey points so that the coefficient of determination $\mathrm{R}^{2}=0.99980$ for the left laser dot and $\mathrm{R}^{2}=0.99986$ for the right laser dot respectively.

Figure 7 shows the calculated values of location deviations of laser dots energy centres after calibration of the measuring set The average deviation of the position of the calibrated energy centres of laser dots traces is 1.16 pixel for the left dot and 0.96 pixel for the right dot respectively. Residual distortion of the CMOS camera affects the distortion values.

Table 4 summarizes the results of calculations on the basis of which the sensitivity of the equipment was determined for 3 observation cycles (distance change between the transmitter and the receiver). Based on these observations, it was possible to calculate the average distance change between energy centres of every individual dot (when the transmitter moved $1 \mathrm{~mm}$ ), which enabled to determine the measuring set accuracy. The precision of the measuring device (sensitivity) was determined for the average movement of laser dots by 1 pixel. The summary of calculated results reveals that the measurement accuracy decreases as the measuring distance increases. The precision of the measurement is inversely proportional to the base ratio $(B / D)$. The measurement precision was respectively: $0.04 \mathrm{~mm}$ for the distance $D=38.5 \mathrm{~cm}$ and $0.20 \mathrm{~mm}$ for $153 \mathrm{~cm}$.

\section{CONCLUSION}

The idea of measuring relative distances between rock blocks with opto-electronic technique that relies on a one-module LMS enables telemetric and automatic observations. Initial research and experimental works using a prototype LMS conducted by the authors in the laboratory have shown that: 
Table 2 Summary of the results of statistical calculations.

\begin{tabular}{|c|c|c|c|c|c|c|}
\hline & \multicolumn{3}{|c|}{ Upper (left) laser dot } & \multicolumn{3}{|c|}{ Bottom (right) laser dot } \\
\hline $\begin{array}{c}\text { coefficient' } \\
\text { index }\end{array}$ & coefficient & $\begin{array}{l}\text { standard } \\
\text { error of the } \\
\text { coefficient }\end{array}$ & t-statistic & coefficient & $\begin{array}{l}\text { standard } \\
\text { error of the } \\
\text { coefficient }\end{array}$ & t-statistic \\
\hline$j$ & $a_{j}$ & $s_{a j}$ & $\left|t_{\text {emp }}\right|$ & $a_{j}$ & $s_{a j}$ & $\left|t_{\text {emp }}\right|$ \\
\hline 1 & $1.48 \mathrm{E}-05$ & $3.10 \mathrm{E}-06$ & 4.79 & $-3.48 \mathrm{E}-05$ & $1.62 \mathrm{E}-05$ & 2.15 \\
\hline 2 & $-1.82 \mathrm{E}-06$ & $7.98 \mathrm{E}-07$ & 2.28 & $2.22 \mathrm{E}-03$ & $9.68 \mathrm{E}-04$ & 2.30 \\
\hline 3 & 0.00073 & 0.00015 & 4.93 & $-7.54 \mathrm{E}-05$ & $3.74 \mathrm{E}-05$ & 2.02 \\
\hline 4 & 0.0100 & 0.0019 & 5.17 & -0.0531 & 0.0208 & 2.55 \\
\hline 5 & 0.0044 & 0.0015 & 2.94 & 0.0041 & 0.0020 & 2.07 \\
\hline 6 & -0.130 & 0.035 & 3.73 & 0.615 & 0.203 & 3.03 \\
\hline 7 & - & - & - & -0.075 & 0.035 & 2.13 \\
\hline 8 & -0.80 & 0.13 & 6.24 & -3.71 & 0.93 & 3.97 \\
\hline 9 & 1.42 & 0.26 & 5.42 & 0.52 & 0.24 & 2.17 \\
\hline 10 & - & - & - & 11.26 & 1.87 & 6.03 \\
\hline 11 & 4.20 & 0.61 & 6.86 & -1.40 & 0.55 & 2.52 \\
\hline 12 & -6.10 & 0.64 & 9.50 & - & - & - \\
\hline 13 & 23.05 & 0.74 & 30.94 & -38.88 & 1.18 & 33.03 \\
\hline \multirow{3}{*}{$\begin{array}{l}\text { constant' } \\
\text { index }\end{array}$} & constant & $\begin{array}{c}\text { standard } \\
\text { error of the } \\
\text { constant }\end{array}$ & t-statistic & constant & $\begin{array}{c}\text { standard } \\
\text { error of the } \\
\text { constant }\end{array}$ & t-statistic \\
\hline & b & $s_{b}$ & $t_{e m p}$ & b & $s_{b}$ & $t_{e m p}$ \\
\hline & -22.48 & 0.34 & 66.49 & -61.98 & 0.28 & 220.01 \\
\hline
\end{tabular}

Table 3 Summary of the results of statistical analyses.

\begin{tabular}{|c|c|c|}
\hline Statistic & $\begin{array}{c}\text { Upper (left) } \\
\text { laser dot }\end{array}$ & $\begin{array}{c}\text { Bottom (right) } \\
\text { laser dot }\end{array}$ \\
\hline $\begin{array}{l}R^{2} \text { - coefficient of determination } \\
n \text { - number of observations }\end{array}$ & 0.99980 & 0.99986 \\
\hline The number of degrees of freedom: $v_{l}=d f_{S S E}$ & 11 & 12 \\
\hline The number of degrees of freedom: $v_{2}=d f_{S S R}$ & 49 & 48 \\
\hline $\begin{array}{l}S_{Y} \text {-standard error of experimental values } Y \\
\qquad \boldsymbol{S}_{\boldsymbol{Y}}=\sqrt{\boldsymbol{M S E}} \\
{[\mathrm{pix}]}\end{array}$ & 1.16 & 0.96 \\
\hline$\alpha$ - significance level & \multicolumn{2}{|c|}{0.05} \\
\hline$t_{a, v 2}-$ critical value of the $t$-Student test & $\begin{array}{c}2.010 \\
223570\end{array}$ & $\begin{array}{c}2.011 \\
278729\end{array}$ \\
\hline F distribution & $1.18 \mathrm{E}-86$ & $6.89 \mathrm{E}-88$ \\
\hline$F_{\alpha, v l, v 2}$ - critical value of the $F$ - test & 1.99 & 1.96 \\
\hline
\end{tabular}

1. the measurement accuracy is better than $\pm 0.06 \mathrm{~mm}$ (about 1 pixel), for the base ratio $(B / D)$ 1:1 and greater;

2. the accuracy with which the laser dot energy centre is identified (the measurement repeatability) is around 0.3 pixel;

3. measurement using a single module enables to determine displacement of rock blocks in one direction. The authors plan to develop prototypes of multi-point measurement modules (in the presented sample options), which will enable the determination of the mutual spatial position of rock blocks (in the XYZ coordinate system).

\section{REFERENCES}

Cacoń, S.: 2001, Problem of reliability of geodetic measurements of deformations of engineering objects in relation object - rock mass. Prace Instytutu Geodezji i Kartografii, XLVIII (102), 131-142, (in Polish).

Brown, D.C.: 1971, Close-range camera calibration. Photogrammetric Engineering, 37(8), 855-866.

Cyganek, B. and Sieber, J.P.: 2009, An Introduction to 3D Computer Vision Techniques and Algorithms. John Wiley \& Sons, Ltd, Chichester, UK, 483 pp.

Freedman, D.A.: 2005, Statistical Models: Theory and Practice. Cambridge University Press, New York, 424 pp.

Hanzl, V.: 2011, Monitoring of rock blocks movements. Acta Montanistica Slovaca, 6, No. 4, 287-290.

Höpcke, W.: 1980, Fehlerlehre und Ausgleichsrechnung (in German). Walter de Gruyter, Berlin New York, 227 pp.

Gołuch, P., Ćmielewski, K. and Kuchmister, J.: 2012, Use of photogrammetric method and laser technology for determining of geometric deviations of the rotary elements. AFKiT, 24, 73-86, (in Polish). 


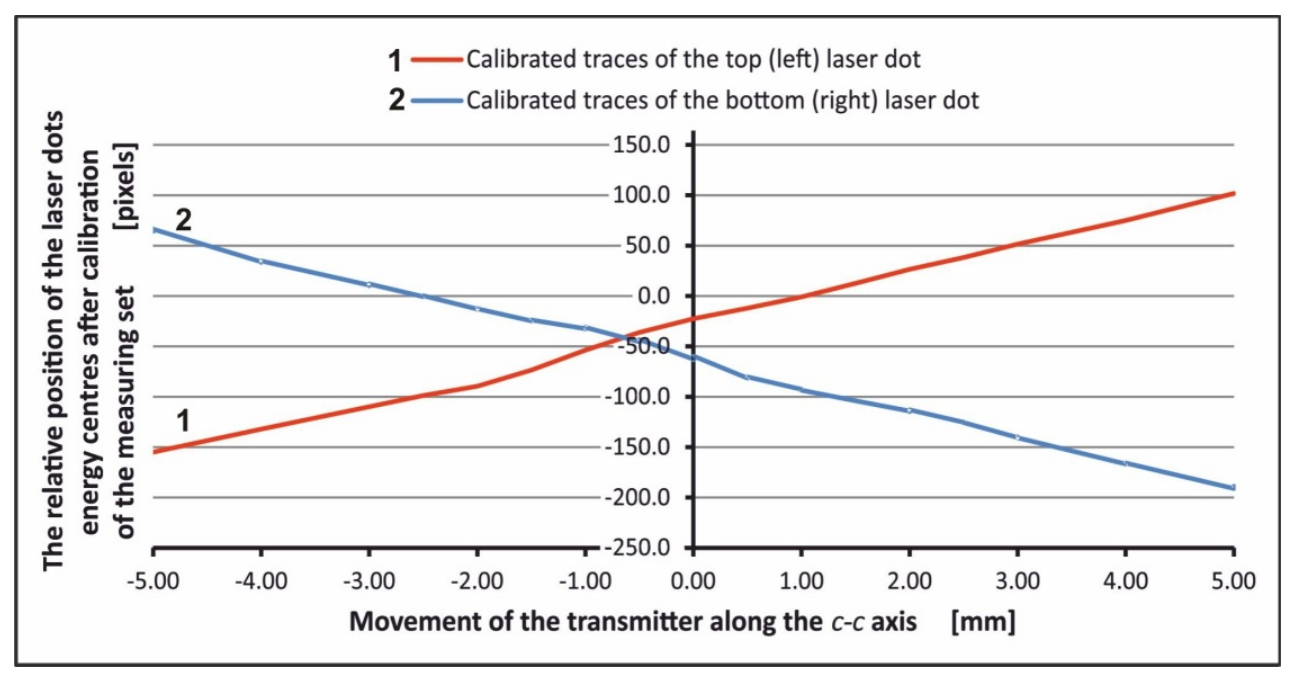

Fig. 6 Repositioning of the calibrated energy centres of laser dots when moving the transmitter along its $c-c$ axis.

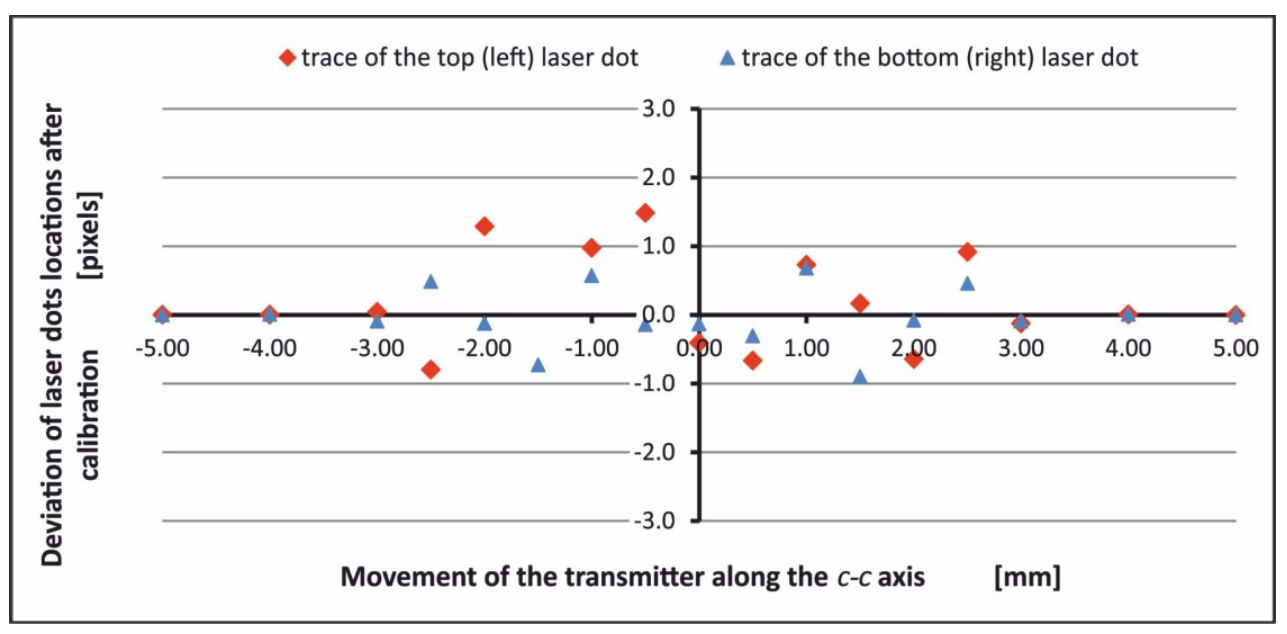

Fig. 7 Residuals of laser dot energy centres locations after LSM calibration.

Table 4 Sensitivity of a measuring instrument.

\begin{tabular}{|c|c|c|c|c|c|c|}
\hline \multirow{2}{*}{ 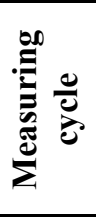 } & \multirow{2}{*}{$\begin{array}{c}\text { Measuring } \\
\text { distance }\end{array}$} & \multirow{2}{*}{$\begin{array}{c}\text { The base } \\
\text { ratio } \\
B / D\end{array}$} & \multicolumn{2}{|c|}{$\begin{array}{l}\text { The average change in the distance } \\
\text { between images of laser dots energy } \\
\text { centres }\end{array}$} & \multicolumn{2}{|c|}{$\begin{array}{c}\text { Device measuring } \\
\text { precision }\end{array}$} \\
\hline & & & $\begin{array}{c}\text { Left } \\
{[\mathrm{pix} / \mathrm{mm}]}\end{array}$ & $\begin{array}{c}\text { Right } \\
{[\mathrm{pix} / \mathrm{mm}]}\end{array}$ & $\begin{array}{l}\text { pix_L } \\
{[\mathrm{mm}]}\end{array}$ & $\begin{array}{l}\text { pix_R } \\
{[\mathrm{mm}]}\end{array}$ \\
\hline I & 38.5 & $2: 1$ & 26.64 & 27.59 & 0.04 & 0.04 \\
\hline II & 78.0 & 1: 1 & 12.01 & 15.42 & 0.08 & 0.06 \\
\hline III & 153.0 & $1: 2$ & 6.53 & 5.03 & 0.15 & 0.20 \\
\hline
\end{tabular}

Gruen, A. and Huan, T.S.: 2001, Calibration and Orientation of Cameras in Computer Vision. Springer-Verlag Berlin Heidelberg New York, 235 pp.

Kavvadas, M.J.: 2003, Monitoring and modelling ground deformations during tunnelling. Proceed. of 11 th FIG International Symposium on Deformation Measurements, Santorini (Greece), 25-38 May, 371389.

Mora, A.S.: 1998, Aplicaciones industriales de la topografía. Colegio Oficial de Ingenieros Técnicos en Topografía, Madrid-Castilla-La Mancha, 367 pp., (in Spain).
Pears, N., Liu, Y. and Bunting, P.: 2012, 3D Imaging, Analysis and Applications. Springer-Verlag London, $499 \mathrm{pp}$.

Pelzer, H.: 1988, Ingenieurvermessung - Deformationsmessungen - Massenberechnung (in German). Ergebnisse des Arbeitskreises 6 des Deutschen Vereins für Vermessungswesen (DVW) e.V. Verlag Konrad Witwer, Stuttgart, 192 pp.

Schofield, W. and Breach, M.: 2007, Engineering surveying - 6th ed. Elsevier Ltd., Oxford, UK, 622 pp. 